\title{
BMJ Global Health One size does not fit all: preventing tuberculosis among child contacts
}

\author{
Daria Szkwarko (D) , ${ }^{1,2}$ Yael Hirsch-Moverman ${ }^{3,4}$
}

To cite: Szkwarko D, Hirsch-Moverman Y. One size does not fit all: preventing tuberculosis among child contacts. BMJ Global Health 2019;4:e001950. doi:10.1136/ bmjgh-2019-001950

Handling editor Seye Abimbola

Received 2 September 2019 Revised 26 November 2019 Accepted 30 November 2019

Check for updates

(c) Author(s) (or their employer(s)) 2019. Re-use permitted under CC BY-NC. No commercial re-use. See rights and permissions. Published by BMJ

${ }^{1}$ Department of Family Medicine, The Warren Alpert School of Medicine at Brown University, Providence, Rhode Island, USA ${ }^{2}$ Department of Family Medicine and Community Health, University of Massachusetts Medical School, Worcester, Massachusetts, USA ${ }^{3}$ ICAP at Columbia University, New York City, New York, USA ${ }^{4}$ Department of Epidemiology, Mailman School of Public Health, New York City, New York, USA

Correspondence to Dr Daria Szkwarko; szkwarkd@gmail.com

\section{INTRODUCTION}

The United Nations General Assembly high-level meeting (HLM) on Ending TB in 2018 brought government leaders and other stakeholders together to highlight the urgent need to address tuberculosis (TB), the leading infectious disease killer worldwide. ${ }^{1}$ In advance of the HLM, the WHO and other organisations, released updated guidance on preventing and treating childhood TB. ${ }^{2}$ The HLM outcome was encouraging with $>100$ countries agreeing to provide 30 million people with TB preventive treatment (TPT), including 4 million young children ( $<5$ years), by the end of 2022 .

Tuberculosis is particularly deadly for children. In 2018, an estimated 1.1 million children developed TB and $>200000$ children died. ${ }^{3} 7.5$ million are exposed to $\mathrm{TB}$ at the household level and are in need of TB evaluation and TPT to avert TB disease. ${ }^{34}$ Young children are particularly vulnerable, and are at risk for disseminated and severe forms of TB. ${ }^{5}$ In 2016, in recognition of the importance of preventing TB among young children, the WHO added TPT initiation for eligible child contacts as an indicator to be collected by countries globally.

TPT is highly effective at preventing TB in all ages. ${ }^{6}$ A modelling study demonstrated that preventing one child TB death would require visiting 48 households where an adult with TB resides, screening 77 children, providing 48 TPT and two TB treatment courses. ${ }^{7}$ Unfortunately, WHO estimates that only $27 \%$ of the 1.3 million TB-exposed young children initiated TPT in 2018, and studies suggest that the number of exposed young children is likely higher. $^{348}$

Effective TB prevention among young children requires implementation of successful child TB contact management, which entails identifying and screening child contacts exposed to adults with TB, and ensuring initiation and completion of either TPT or TB treatment. National TB programme (NTPs)

\section{Summary box}

Tuberculosis (TB) preventive treatment (TPT) is highly effective at preventing TB cases and deaths in children, yet only a quarter of children eligible for TPT globally receive it.

- The WHO roadmap for childhood TB recommends an 'integrated, family and community-centered strategy,' yet, there is no clear guidance on how to operationalise such a strategy and common strategies may not serve all the diverse needs of unique families whose children are in need of TB prevention services.

- This article presents a flexible child contact management (CCM) framework, which goes beyond the traditional approaches of either facility-based or community-based, and can be customised for each child and their family's needs.

- Strengthening the WHO health system building blocks, such as health information systems and health service delivery, could help provide infrastructure and support for a flexible CCM framework.

recommend that healthcare workers (HCWs) use standardised child contact management (CCM) approaches to facilitate delivery of all cascade services/steps. The traditional CCM approach is facility-based, where all CCM cascade steps are conducted at the health facility. ${ }^{9}{ }^{10}$ An alternative approach aims to provide CCM services in the community (in households or community centres). ${ }^{11} 12$ At times, a combination of both approaches is implemented where for example, identification and symptom screening occur in the community and evaluation and treatment happen at the facility. ${ }^{13}{ }^{14}$ Standardised approaches coupled with renewed interest in childhood TB and WHO reporting requirements have led to some improvement in TPT initiation among TB-exposed young children globally from $13 \%$ in 2016 to $27 \%$ in 2018. ${ }^{315}$ Despite this improvement, TPT initiation remains suboptimal due to many CCM implementation challenges in low-resource, high TB incidence countries that jeopardise its success. 


\section{BARRIERS TO CHILD CONTACT MANAGEMENT}

In 2017, a systematic review studied CCM barriers in high TB burden countries. Individual barriers include knowledge gaps (both among family members and HCWs), access-to-care, stigma, competing priorities and treatmentrelated challenges; health system barriers include health system infrastructure such as lack of government/NTP prioritisation, limited staff resources, and lack of tools to support monitoring and evaluation. ${ }^{16}$ These challenges create losses at every CCM cascade step, from identification of child contacts, to TB evaluation, TPT initiation, and TPT completion. Interestingly, although many of the above barriers were described as individual barriers, some are a direct result of inflexible and underfunded health systems that do not prioritise patients' needs. Furthermore, barriers are inter-related and often stem from broader systemic issues like poverty and education inequality. For example, if we consider access-to-care, a child may be unable to access care because while their caregiver is worried about stigma associated with a HCW visiting the household, they lack funds to bring the child to the facility. Stigma may exist due to lack of prioritisation of community and HCW education. For another child, their caregiver may be more worried about stigma when visiting a facility despite being able to afford transport to bring a child in for evaluation. A standardised framework in this one community may not serve the diverse needs of children in need of TB prevention services.

In order to continue an upward trajectory of TPT initiation, it is crucial to recognise that barriers that impede successful CCM vary from family to family, even within the same community. A pilot study from Lesotho demonstrated that caregivers were interested in being involved in their children's treatment decisions. ${ }^{17}$ The WHO roadmap for childhood TB recommends an 'integrated, family and community-centred strategy'. ${ }^{2}$ Yet, there is no clear guidance on how health systems can operationalise such a strategy. We propose a flexible CCM framework, which goes beyond standardised approaches and provide suggestions on how health systems could support a framework that is customised for each child's/family's needs.

\section{Flexible CCM framework}

The premise of this framework is that 'one size does not fit all'. Thus, we propose that health systems and NTPs train HCWs to accomplish each CCM cascade step depending on the child's/family's unique circumstances. Traditionally, the majority of NTPs encourage that child contacts move through the CCM cascade in a structured fashion. In a flexible CCM framework, each child contact would flow through each CCM cascade step based on their family's needs. A flexible approach to identification could begin in the facility with a family-centred discussion with the adult with TB using a shared-decision making approach. If the child can be brought to the facility, the HCW would invite them to come in for screening. If the child cannot come to the facility, the HCW would visit the household. A flexible approach to screening would depend on the

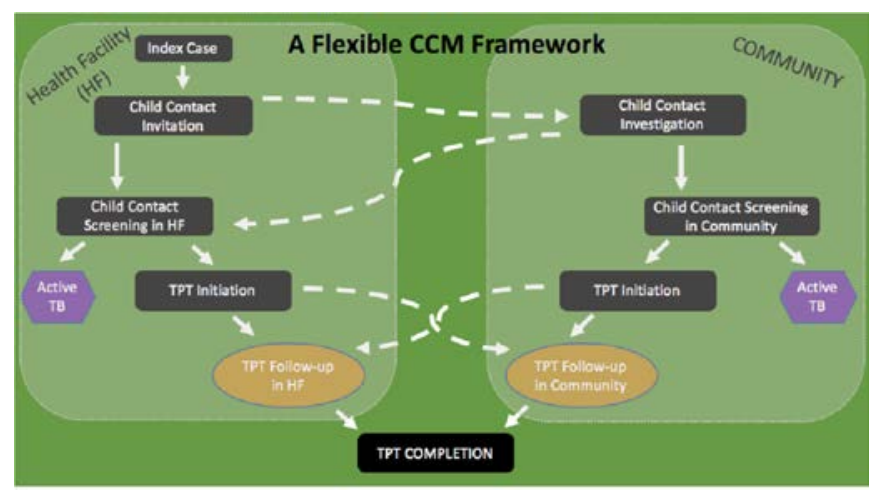

Figure 1 A flexible CCM framework. CCM, child contact management; TB, tuberculosis; TPT, TB preventive treatment.

health system's capacity as well as a family-centred discussion. In most areas, symptomatic child contacts would need to report to the facility to finish the screening process due to limited availability of mobile x-ray. Asymptomatic child contacts would be screened via history and physical examination in the facility or community. Once active TB disease has been ruled out, TPT would be initiated. A flexible approach to TPT initiation would include a family-centred discussion and shared-decision making. If TPT provision is made available in both the facility and the community, both options would be presented to the family, and TPT would need to be available at both facility and community levels. Follow-up of child contacts on TPT can occur in the facility or the community based on family's preferences. (figure 1, table 1)

\section{Health system strengthening for a flexible CCM framework}

For health systems to support a flexible CCM framework, a broader effort to strengthen and monitor health systems is needed. The WHO describes six core building blocks for health systems strengthening. ${ }^{18}$ In particular, strengthening two of these components, health information systems and health service delivery, could lead to an improved infrastructure that would support personcentred strategies such as a flexible CCM framework.

Health information systems strengthening incorporates enhancing access of information to diverse users throughout the health system so it is reliable, accessible, and comprehensible. It also includes monitoring and evaluating data related to supply chain so that X-ray availability or TPT drug supply would be routinely tracked and communicated to HCWs to decrease evaluation barriers and stock-outs. Expansion and integration of electronic health record systems can enable all aspects of care to be tracked everywhere-in facilities or communities. Therefore, a HCW seeing a child in an outpatient clinic for a skin infection should be able to easily see electronically that this child has been identified as potentially eligible for TPT at a nearby facility.

Health service delivery incorporates service quality which ultimately integrates staff training. Longitudinal training and mentorship for HCWs could occur using 
Table 1 A child contact's journey through the CCM cascade in commonly available models and an example of challenges that could be overcome by a flexible model

\begin{tabular}{|c|c|c|c|}
\hline & Facility & Community & $\begin{array}{l}\text { Example of challenges overcome by a flexible } \\
\text { framework }\end{array}$ \\
\hline Identification & $\begin{array}{l}\text { An adult with TB is invited to bring } \\
\text { child contacts aged }<5 \text { years into } \\
\text { the facility for TB screening by } \\
\text { HCWs. }\end{array}$ & $\begin{array}{l}\text { A household where the adult } \\
\text { with TB resides is visited by } \\
\text { HCWs to investigate if any } \\
\text { child contacts aged }<5 \text { years } \\
\text { lives in the household. }\end{array}$ & $\begin{array}{l}\text { An adult with TB reveals that they only see their } \\
\text { children over the weekend in a rural area. The HCW } \\
\text { confirms that the adult with TB's partner would } \\
\text { be open to a household visit and communicates } \\
\text { this with a colleague at the closest facility to } \\
\text { the partner's home. This communication and } \\
\text { identification of the child contact is tracked in an } \\
\text { electronic system. }\end{array}$ \\
\hline Screening & $\begin{array}{l}\text { Child contacts are screened in the } \\
\text { facility. } \\
\text { Several evaluation algorithms } \\
\text { exist globally so screening and } \\
\text { diagnostic testing may vary. }\end{array}$ & $\begin{array}{l}\text { Child contacts are screened } \\
\text { in the community, that is, } \\
\text { household or community } \\
\text { centre. } \\
\text { Several evaluation algorithms } \\
\text { exist globally so screening and } \\
\text { diagnostic testing may vary. } \\
\text { Some programmes may have } \\
\text { the capacity to conduct mobile } \\
\text { diagnostics in the community. }\end{array}$ & $\begin{array}{l}\text { A community health volunteer (CHV) from the } \\
\text { partner's nearby facility visits the child's home. } \\
\text { It becomes clear that this family cannot afford } \\
\text { bringing the asymptomatic child to the health } \\
\text { facility for evaluation. The CHV seeks guidance } \\
\text { the following week through mentors via a virtual } \\
\text { telementoring programme and receives affirmation } \\
\text { that TPT can be started given the child is } \\
\text { asymptomatic. }\end{array}$ \\
\hline TPT initiation & TPT is initiated at the facility. & $\begin{array}{l}\text { TPT is initiated in the } \\
\text { community, that is, household } \\
\text { or community centre. If in } \\
\text { the household, HCWs carry } \\
\text { medication and a light-weight } \\
\text { scale to the home. If in a } \\
\text { community centre, medication } \\
\text { is stored there. }\end{array}$ & $\begin{array}{l}\text { Since the family has limited funds, shared-decision } \\
\text { making among the adult with TB, their partner, their } \\
\text { HCW, and the CHV at the nearby facility leads to a } \\
\text { plan for the adult with TB to pick up medications } \\
\text { (based on child's weight) for the child at their } \\
\text { healthcare facility, and bring the medication home } \\
\text { for the child over the weekend to initiate TPT. The } \\
\text { CHV visits the household to confirm initiation. }\end{array}$ \\
\hline TPT completion & $\begin{array}{l}\text { TPT follow-up occurs monthly in } \\
\text { the facility to monitor adherence } \\
\text { and side effects and distribute } \\
\text { medication refills. This can happen } \\
\text { via child contacts reporting monthly } \\
\text { with adults with TB/caregivers or } \\
\text { with careful verbal reporting via } \\
\text { adults with TB/caregivers so that } \\
\text { child contacts do not need to come } \\
\text { into the facility every month. }\end{array}$ & $\begin{array}{l}\text { TPT follow-up occurs monthly } \\
\text { in the community, that is, } \\
\text { household or community } \\
\text { centre, to monitor adherence } \\
\text { and side effects and distribute } \\
\text { medication refills. }\end{array}$ & $\begin{array}{l}\text { The CHV visits the household monthly to monitor } \\
\text { for side effects and weigh the child. This weight is } \\
\text { reported to the healthcare worker at the adult with } \\
\text { TB's facility who checks the dosing and prescribes } \\
\text { the appropriate TPT monthly. The adult with TB } \\
\text { picks up the medication at their visits eliminating } \\
\text { unnecessary travel and decreasing financial burden } \\
\text { on the family. }\end{array}$ \\
\hline
\end{tabular}

HCWs, Healthcare workers including doctors, nurses, community health volunteers, or lay workers, who are associated with health facilities and provide care to patients.

CMM, child contact management; TB, tuberculosis; TPT, TB preventive treatment.

less expensive telementoring modalities like the ECHO modelTM that increase HCW knowledge and patient access-to-care. ${ }^{19}$ Additionally, a person-centeredness approach, that is, services that are organised around the person rather than disease or financing, is recommended. The WHO has a framework for integrated people-centered health services. ${ }^{20}$ Person-centered care is oriented toward addressing patients' priorities as a holistic model of healthcare delivery that considers the patient as the central figure in the process/continuum of care. Thus a person-centred approach is not a one size fits all solution to the multifactorial barriers that have been identified, but rather a flexible model of care that reacts to the specialised needs of individuals. ${ }^{16}$

\section{CONCLUSION}

Given the significant burden of TB disease in young children, the continued challenges in diagnosing TB in children, and its severe sequelae, ${ }^{41}$ TB prevention is a salient public health issue. Moving beyond traditional CCM constructs is critically important given that every individual, family, community, facility, TB programme, and country vary greatly. Therefore, the CCM journey for each adult with TB and their child contacts should be family-centred and flexible. CCM barriers that appear to be individually-based are often a result of larger, systemic issues and vary greatly. It is imperative that health systems consider an individual family's unique CCM barriers and meet the child/family where they are. Using existing frameworks for broader health system strengthening and integrated people-centred care can support a flexible CCM model. Implementing a flexible CCM framework that incorporates shared-decision making between HCWs and families at every step may enhance efforts to increase TB preventive services and decrease TB burden in vulnerable children.

Acknowledgements Wafaa El-Sadr, E. Jane Carter, Karen du Preez. 
Contributors DS and YH-M contributed equally to the conception, writing and editing of this manuscript. E. Jane Carter, Wafaa El-Sadr and Karen Du Preez provided technical editing for this manuscript.

Funding $\mathrm{YH}-\mathrm{M}$ was funded by the National Institutes on Allergy and Infectious Diseases (NIAID) of the National Institutes of Health (NIH) (K01Al104351). DS is partially supported by Institutional Development Award Number U54GM115677 from the National Institute of General Medical Sciences of the National Institutes of Health, which funds Advance Clinical and Translational Research (Advance-CTR). DS is also partially supported by the Thrasher Research Fund.

Disclaimer The content is solely the responsibility of the authors and does not necessarily represent the official views of National Institutes of Health and the Thrasher Research Fund.

Competing interests None declared.

Patient consent for publication Not required.

Provenance and peer review Not commissioned; externally peer reviewed.

Data availability statement Data is not available.

Open access This is an open access article distributed in accordance with the Creative Commons Attribution Non Commercial (CC BY-NC 4.0) license, which permits others to distribute, remix, adapt, build upon this work non-commercially, and license their derivative works on different terms, provided the original work is properly cited, appropriate credit is given, any changes made indicated, and the use is non-commercial. See: http://creativecommons.org/licenses/by-nc/4.0/.

ORCID iD

Daria Szkwarko http://orcid.org/0000-0001-5864-9011

\section{REFERENCES}

1 United Nations. Political Declaration of the un General assembly high-level meeting on the fight against tuberculosis. New York: UNHQ, 2018. https://www.who.int/tb/unhlmonTBDeclaration.pdf

2 World Health Organization. Roadmap towards ending TB in children and adolescents. Geneva, Switzerland, 2018. Available: https://apps. who.int/iris/bitstream/handle/10665/274374/9789241514668-eng. pdf [Accessed 1 May 2019].

3 World Health Organization. Global tuberculosis report 2019. Geneva, Switzerland: WHO, 2019. https://apps.who.int/iris/bitstream/handle/ 10665/329368/9789241565714-eng.pdf?ua=1

4 Dodd PJ, Gardiner E, Coghlan R, et al. Burden of childhood tuberculosis in 22 high-burden countries: a mathematical modelling study. Lancet Glob Health 2014;2:e453-9.

5 Marais BJ, Gie RP, Schaaf HS, et al. The natural history of childhood intra-thoracic tuberculosis: a critical review of literature from the prechemotherapy era. Int J Tuberc Lung Dis 2004;8:392-402.
6 Mount FW, Ferebee SH. Preventive effects of isoniazid in the treatment of primary tuberculosis in children. $N$ Engl J Med 1961;265:713-21.

7 Dodd PJ, Yuen CM, Becerra MC, et al. Potential effect of household contact management on childhood tuberculosis: a mathematical modelling study. Lancet Glob Health 2018;6:e1329-38.

8 Yuen CM, Jenkins HE, Chang R, et al. Two methods for setting child-focused tuberculosis care targets. Public Health Action 2016;6:83-96.

9 Szkwarko D, Owiti P, Buziba N, et al. Implementation of an active, clinic-based child tuberculosis contact management strategy in Western Kenya. Public Health Action 2018;8:91-4.

10 Claessens NJM, Gausi FF, Meijnen S, et al. Screening childhood contacts of patients with smear-positive pulmonary tuberculosis in Malawi. Int J Tuberc Lung Dis 2002;6:362-4.

11 Hirsch-Moverman Y, Howard AA, Frederix K, et al. The prevent study to evaluate the effectiveness and acceptability of a communitybased intervention to prevent childhood tuberculosis in Lesotho: study protocol for a cluster randomized controlled trial. Trials 2017;18:552

12 Yassin MA, Datiko DG, Tulloch O, et al. Innovative community-based approaches doubled tuberculosis case notification and improve treatment outcome in southern Ethiopia. PLoS One 2013;8:e63174

13 Shivaramakrishna HR, Frederick A, Shazia A, et al. Isoniazid preventive treatment in children in two districts of South India: does practice follow policy? Int J Tuberc Lung Dis 2014;18:919-24.

14 Thind D, Charalambous S, Tongman A, et al. An evaluation of 'Ribolola': a household tuberculosis contact tracing programme in North West Province, South Africa. Int J Tuberc Lung Dis 2012;16:1643-8.

15 World Health Organization. Global tuberculosis report 2017. Geneva, Switzerland: WHO, 2017. http://apps.who.int/iris/bitstream/10665/ 259366/1/9789241565516-eng.pdf?ua=1. (Accessed Dec 26, 2017).

16 Szkwarko D, Hirsch-Moverman Y, Du Plessis L, et al. Child contact management in high tuberculosis burden countries: a mixedmethods systematic review. PLoS One 2017;12:e0182185.

17 Hirsch-Moverman Y, Mantell JE, Lebelo L, et al. Tuberculosis preventive treatment preferences among care givers of children in Lesotho: a pilot study. Int J Tuberc Lung Dis 2018;22:858-62.

18 World Health Organization. Monitoring the building blocks of health systems: a Handbook of indicators and their measurement strategies. Geneva Switzerland: WHO, 2010. https://www.who.int/ healthinfo/systems/WHO_MBHSS_2010_full_web.pdf?ua=1

19 Zhou C, Crawford A, Serhal E, et al. The impact of Project echo on participant and patient outcomes: a systematic review. Acad Med 2016;91:1439-61.

20 World Health Organization. Framework on integrated, peoplecentred health services. Sixty-ninth World health assembly, 2016. Available: http://apps.who.int/gb/ebwha/pdf_files/WHA69/A69_39en.pdf?ua=1 [Accessed 20 Oct 2019].

21 Detjen AK, DiNardo AR, Leyden J, et al. Xpert MTB/RIF assay for the diagnosis of pulmonary tuberculosis in children: a systematic review and meta-analysis. Lancet Respir Med 2015;3:451-61. 